\title{
INGESTIVE BEHAVIOUR AND PHYSIOLOGY OF THE MEDICINAL LEECH
}

\author{
BY CHARLES M. LENT ${ }^{1}$, KARSTEN H. FLIEGNER*, EDWARD \\ FREEDMAN $\dagger$ AND MICHAEL H. DICKINSON $\ddagger$ \\ 'Department of Biology, Utah State University, Logan UT 84322 and Division of \\ Biology and Medicine, Brown University, Providence RI 02912, USA
}

Accepted 16 February 1988

\begin{abstract}
Summary
Ingestion lasts $25 \mathrm{~min}$ in Hirudo medicinalis and is characterized by pharyngeal peristalsis which fills the crop. This peristalsis has an initial rate of $2.4 \mathrm{~Hz}$ which decays smoothly to $1.2 \mathrm{~Hz}$ at termination of ingestion. During ingestion, the leech body wall undergoes peristalsis which appears to aid in filling the crop diverticula. Body peristalsis begins at a rate of $10 \mathrm{~min}^{-1}$ and decreases linearly to $2 \mathrm{~min}^{-1}$ at termination. The body also undergoes dorsoventral flexions when blood flow is occluded. Blood meal size increases slightly with leech size: $8.4 \mathrm{~g}$ for 1-g leeches and $9.7 \mathrm{~g}$ for $2-\mathrm{g}$ leeches. However, relative meal size decreases markedly with increasing animal size; from 8.15 times body mass for $1 \mathrm{~g}$ to 4.80 times for $2 \mathrm{~g}$ leeches. When intact leeches were exposed to micromolar concentrations of serotonin, there was an increase in the rate of pharyngeal peristalsis and the size of the blood meals.

Leeches excrete the plasma from their ingested blood meals. Excretion is activated during ingestion, which increases feeding efficiency by increasing the proportion of blood cells in the ingestate. Excretion continues for 4-6 days following ingestion, removing all the remaining plasma from the ingestate. Leech ingestion comprises stereotyped muscular movements, secretion of saliva and excretion of plasma. A strikingly similar feeding physiology is seen in the bloodsucking insect Rhodnius, and we suggest that efficient sanguivory may require the convergent evolution of similar ingestive mechanisms.
\end{abstract}

\section{Introduction}

Ingestion is the consummatory phase of leech feeding behaviour. In Hirudo medicinalis, it is initiated by both chemical (Elliot, 1986) and thermal stimuli

* Present address: School of Medicine, New York University, New York, NY 10016, USA.

$\dagger$ Present address: Department of Neurobiology and Behavior, Cornell University, Ithaca, NY 14853, USA.

$\ddagger$ Present address: Department of Zoology, University of Washington, Seattle, WA 98195, USA.

Key words: behaviour, excretion, ingestion, leech, sanguivory, serotonin. 
(Dickinson \& Lent, 1984). A hungry leech attaches the anterior sucker to the host and cuts the skin with three semicircular jaws. Blood flows into the buccal cavity and is pumped into the crop by rhythmic pharyngeal peristalsis. Leech saliva contains a powerful anticoagulant hirudin (Haycraft, 1884) and is secreted from the cutting edges of the jaws (Marshall, 1984).

Hirudo are distended by meals of 7-9 times their pre-fed mass (Dickinson \& Lent, 1984), and the resulting distension of the body wall terminates ingestion and inhibits biting (Lent \& Dickinson, 1987). Clear fluid flows copiously from the skin of leeches as they feed (Worth, 1951) and, after termination, excess water and salts are excreted from the ingested blood via the paired, segmental nephridia (ZerbstBoroffka, 1973).

Leech ingestion is evoked by the activity of identified neurones (Lent \& Dickinson, 1984). These cells release serotonin, a neurotransmitter which affects both behavioural and physiological components of ingestion. The practice of leeching is now re-emerging in medicine (Lent, 1986), and here we describe the stereotyped movements and glandular activities underlying ingestion by the medicinal leech. An abstract of some of the research reported here has been published (Lent, Fliegner \& Freedman, 1986).

\section{Materials and methods}

Hirudo were obtained from European suppliers and maintained on a $12 \mathrm{~h}: 12 \mathrm{~h}$ light: dark cycle at $15^{\circ} \mathrm{C}$ in glass aquaria filled with artificial pond water (Muller, Nicholls \& Stent, 1981). The leeches weighed between 0.9 and $2.7 \mathrm{~g}$ and were fed at $37^{\circ} \mathrm{C}$ upon 'artificial blood' a $50 \mathrm{vols} \%$ suspension of human erythrocytes in Leibovitz L-15 culture medium (Microbiological Association, Bethesda, MD). In most experiments, sodium heparin was added as an anticoagulant $\left(0.2 \mathrm{mg} \mathrm{ml}^{-1}\right)$. Blood was prepared volumetrically, warmed to $38^{\circ} \mathrm{C}$ and poured into $15 \mathrm{ml}$ polystyrene centrifuge tubes. The open end of the feeding tube was covered with a single layer of Parafilm and the tapered end removed, a procedure which facilitated flow and allowed for the addition of blood. In approximately half the feeding trials, an additional volume of fresh blood at $38^{\circ} \mathrm{C}$ was added to the tube after $10-15$ min of feeding.

\section{Behaviour}

Hirudo were weighed individually and offered the film-covered end of the feeding tube. Hungry leeches attached within a few seconds and their normal exploration of the warm tube was restricted to the film surface by means of a sleeve of Tygon tubing. Once a Hirudo had bitten the film and began to ingest blood, a timer was started and the sleeve was removed. The feeding tube, with the leech attached, was positioned in a 1-1 glass beaker containing pond water and secured to a rigid bar (Fig. 1). Most leeches initiated feeding with only the anterior sucker attached to the film, but in those instances in which a leech had both sucker attached, we dislodged the posterior one to obtain a clear view of the head. 


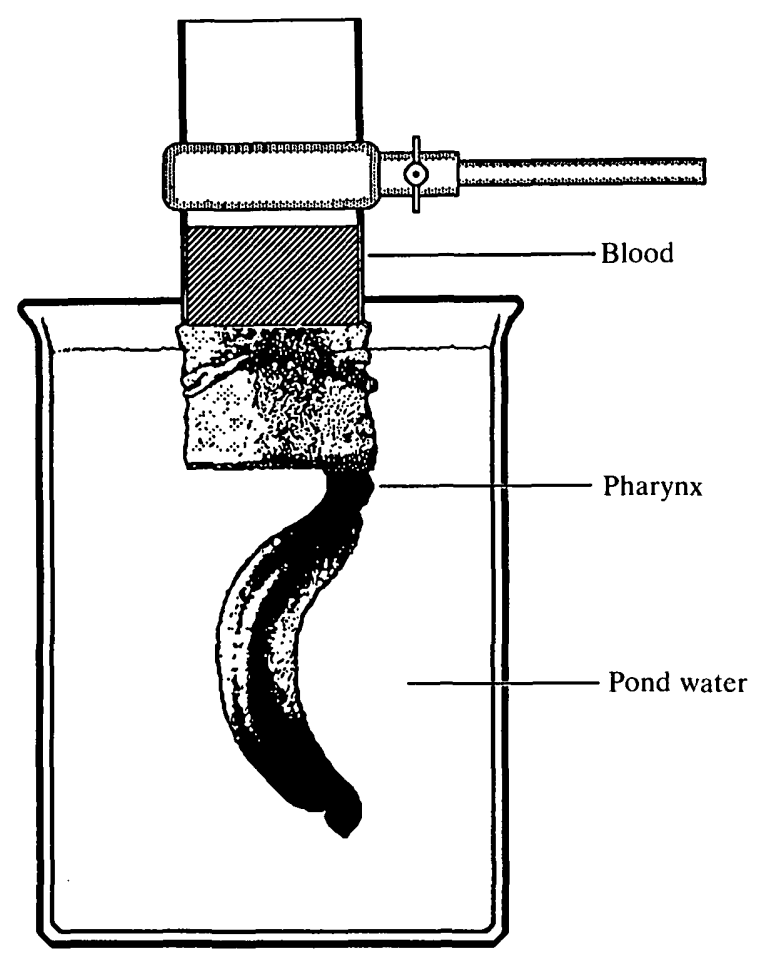

Fig. 1. A diagram showing Hirudo feeding on the artificial blood in a centrifuge tube through Parafilm. Pharyngeal peristalses move the leech head visibly and body movements can be readily seen. Hirudo and the Parafilm were digitized from a photograph and the apparatus was drawn.

Behaviour during ingestion was observed visually. Pharyngeal contractions were counted for $10 \mathrm{~s}$ at the beginning of an ingestive bout and then at 5-min intervals until ingestion was terminated. Body wall peristalses and dorsoventral flexions were recorded continuously on an event recorder (Esterline-Angus). When leeches were satiated, they detached from the Parafilm and the timer was stopped. Leeches were recovered from the beaker immediately and weighed to calculate the size of ingested blood meals. The absolute meal size was calculated by substracting the initial mass of the leech from its final mass. The relative mass of the ingested blood was calculated as (final mass - initial mass) $\times\left(\right.$ initial mass) $^{-1}$.

\section{Serotonin}

To examine the effects of serotonin (5-hydroxytryptamine, 5-HT) upon ingestion, intact animals were bathed in dilute solutions of 5-HT in pond water immediately prior to feeding (Glover \& Kramer, 1982). The time of exposure varied with the 5-HT concentration and leeches were bathed in either 3 or $10 \times 10^{-5} \mathrm{moll}^{-1} 5$-HT for 20 or $2 \mathrm{~min}$, respectively. The 5-HT-treated leeches Were fed while suspended in pond water and behaviour was observed as above. Weighing and timing procedures were also identical. 


\section{Excretion}

To evaluate the effects of postingestive excretion upon body mass, fed leeches were reweighed at daily intervals. Haematocrit (ratio of erythrocytes to total blood volume) was used as an index of the effects of excretion upon the ratio of blood cells to plasma in the ingestate. To obtain samples of ingested blood, the posterior one-third of fed leeches was immersed in $3 \mathrm{moll}^{-1} \mathrm{NaCl}$ for approximately $15 \mathrm{~s}$. This stimulus usually caused regurgitation, a response in which we frequently assisted the leech by firmly squeezing the body. Crop contents were regurgitated onto a stainless-steel pan, and immediately five replicate samples were collected by capillarity into $1 \times 75 \mathrm{~mm}$ microhaematocrit tubes. One end of each tube was sealed with clay (Critoseal, Biological Research, St Louis, MO), and tubes were spun for $10 \mathrm{~min}$ in a clinical centrifuge at $2500 \mathrm{rev} \cdot \mathrm{min}^{-1}$. The packed cell to plasma ratio was measured with a standard haematocrit reader. Haematocrit of the artificial blood samples was measured identically. Feeding behaviour of the leech moved the Parafilm and appeared to prevent any settling of blood cells. Nevertheless, to avoid settling, fresh blood at $38^{\circ} \mathrm{C}$ was added to the feeding tube, and was stirred at least four times during excretion experiments. This procedure maintained a relatively constant height of warm, homogeneous blood in the feeding tube.

Animal size is reported as the median mass $x \pm$ range, in grams. Data-are presented as the arithmetic mean $\bar{x} \pm 1$ S.E.M. ( $N$, number of observations) unless otherwise noted, and statistical tests were performed according to procedures detailed by Sokal \& Rohlf (1981).

\section{Results}

\section{Behaviour}

Under the experimental conditions, Hirudo ingested blood for an average of $24.7 \pm 1.2 \min (N=50)$. As ingestion began, there were extensive contractions of the body for 1-3 min. The body then elongated and pharyngeal peristalsis could easily be discerned outside the anterior end. The duration of ingestive behaviour was influenced by the initial mass of the leech; small leeches ingested blood for slightly longer than large ones (Fig. 2A). In contrast, duration of ingestion was unaffected by the final mass of the leech and its blood meal (Fig. 2B). The duration of leech ingestive behaviour ranged from 14.4 to $47.5 \mathrm{~min}$ and, to analyse the muscular movements of ingestion statistically, durations were normalized to a value of $1 \cdot 0$.

\section{Pharyngeal peristalsis}

Leech ingestion is effected by peristaltic contractions of the pharynx pumping blood into a distensible crop. These rhythmic movements constitute the definitive characteristic of ingestion and are visible externally on the head of the leech. Data on pharyngeal peristalsis were collected from 27 leeches $(1-2.5 \mathrm{~g})$. As ingestior began, the initial pharyngeal frequency was $2.35 \mathrm{~Hz}$ (Fig. 3A). The rate of 


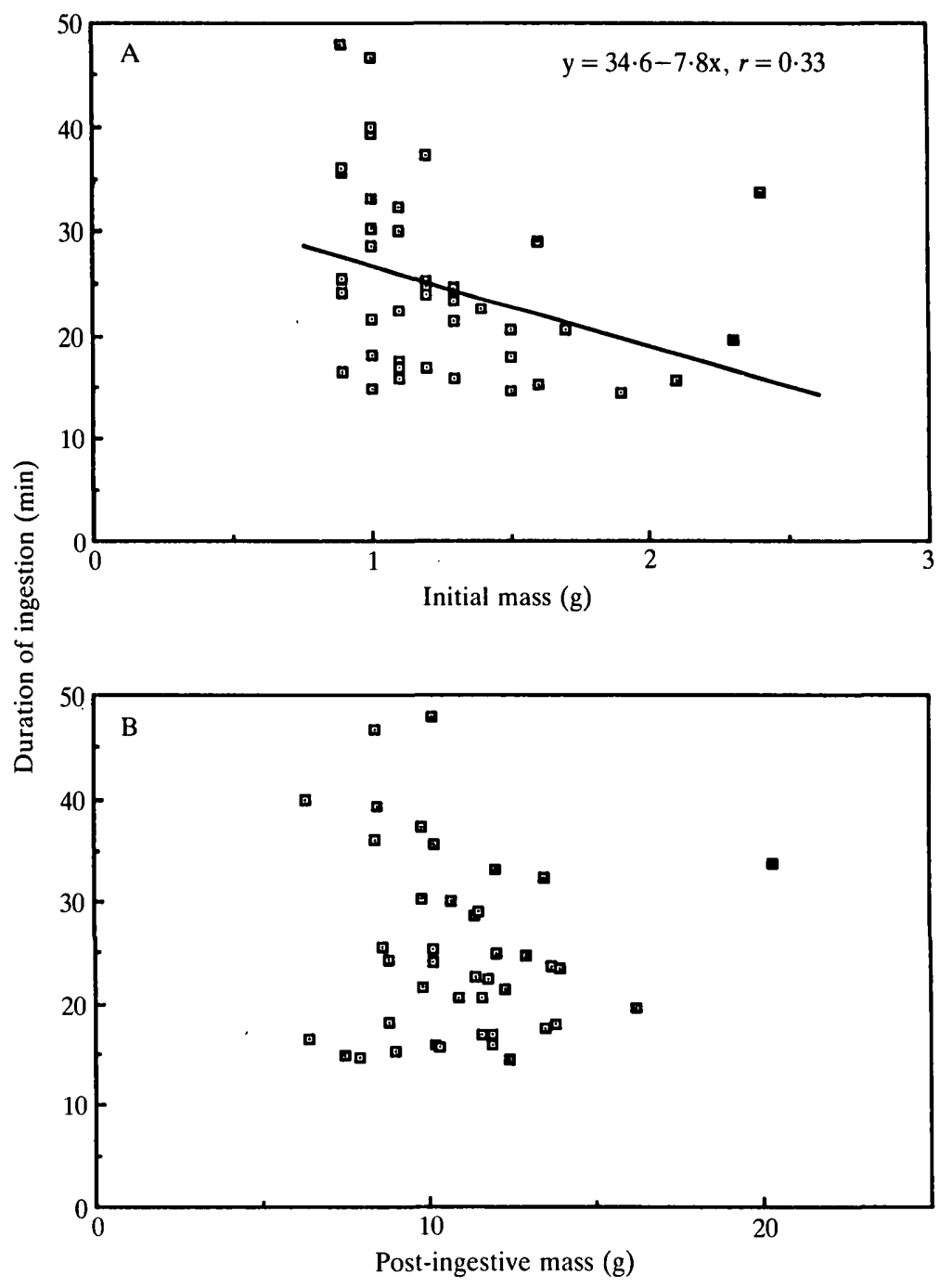

Fig. 2. Duration of Hirudo ingestion. (A) Duration decreases with the initial mass of the leech. The least squares regression differs significantly from zero $(P<0.05)$. (B) Duration of ingestion is independent of the final mass of the leech and its blood meal.

pharyngeal movements then decreased smoothly and continuously until it reached approximately $1.2 \mathrm{~Hz}$ and ingestion was terminated. Peristalsis usually ceased a few seconds before the leech detached from the Parafilm. The frequency was linearly related to the natural logarithm of the period $(r=0.99)$ and appeared to approach an asymptote of $1 \cdot 17 \mathrm{~Hz}$ at the end of ingestion.

It will be seen below that leech size affects several components of ingestion, so to resolve any effects of size on pharyngeal movements, the above data were divided about the median of $1.75 \mathrm{~g}$ into two size groups: $1-1.70 \mathrm{~g}$ and $1.80-2.5 \mathrm{~g}$. 
Small Hirudo contracted the pharynx at higher frequencies than large ones, and it can be seen in Fig. 3B that small leeches had an initial rate of $2.7 \mathrm{~Hz}$ and large ones $2 \cdot 1 \mathrm{~Hz}$. The frequency of both size groups decayed smoothly with a similar temporal relationship: a linear decrease in frequency over the logarithm of the period. The asymptotic pharyngeal frequency of the small leeches was $1.60 \mathrm{~Hz}$ and of large leeches $0.92 \mathrm{~Hz}$. The pharyngeal rates of the two size groups are displaced

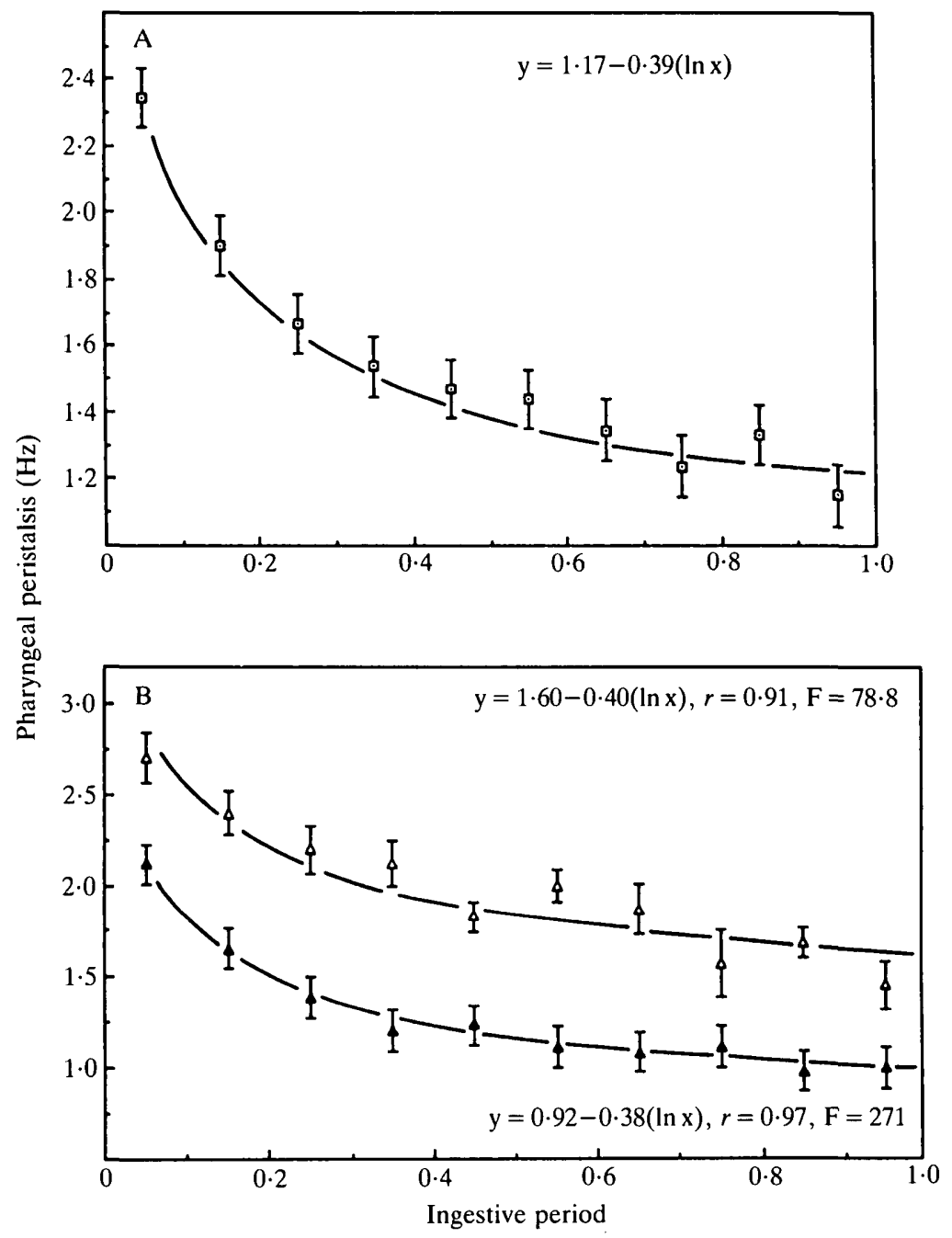

Fig. 3. Pharyngeal peristalsis of Hirudo decays logarithmically during ingestion. (A) Pharyngeal frequency of 27 leeches (range $1 \cdot 0-2 \cdot 5 \mathrm{~g}$, as arithmetic mean \pm 1 S.E.M.). The initial frequency of $2 \cdot 35 \mathrm{~Hz}$ decreases to $1.2 \mathrm{~Hz}$ at termination of ingestion. The plotted line represents the equation: frequency $=1 \cdot 17-0 \cdot 38 \times \ln$ period $(r=0.99 ; \mathrm{F}=513)$. (B) Pharyngeal frequencies of small $(\triangle, 1.0-1.70 \mathrm{~g})$ and large $(\boldsymbol{\Lambda}, 1 \cdot 80-2 \cdot 5 \mathrm{~g})$ leeches decay logarithmically. The slopes of the two groups are similar but their asymptotic values differ. The 33 min range of feeding times enabled these data to be divided into 10 modal increments. Horizontal error bars are omitted. 
vertically from one another by approximately $0.6 \mathrm{~Hz}$ throughout the ingestive period.

\section{Body wall movements}

The body of Hirudo undergoes visible movements as blood is ingested. The most regular of these body movements is peristalsis, which also includes antiperistaltic movements. Peristalses of the body wall were slower and more variable than those of the pharynx and had an initial rate of $10 \mathrm{~min}^{-1}$ (Fig. 4). These movements decreased to about $2 \mathrm{~min}^{-1}$ at termination of ingestion and the rate of change during the period of ingestion was linear $(r=0.97)$. Peristaltic and antiperistaltic body movements appeared to be more robust during the earlier than the later phases of feeding.

Sinusoidal, dorsoventral flexions of the leech body, which resembled those of swimming (Kristan, Stent \& Ort, 1974), occasionally interrupted the peristaltic body movements. These flexions were less regular than peristalses, and are not depicted graphically. The initial rate of flexions was $6 \mathrm{~min}^{-1}-$ approximately half that of peristalses - and they decreased linearly until ingestion was terminated. The rate decreased more slowly for flexions than for peristalses, and at termination of ingestion, both rates were $2 \mathrm{~min}^{-1}$. When dorsoventral flexions were seen, their amplitudes appeared to be larger in the later phases of feeding. We found flexions were correlated with the presence of clots inside the Parafilm covering the feeding tube. After removing the occluding clots, flexions usually disappeared. However, on some occasions flexions persisted, but with decreased amplitude. In later experiments, we added the anticoagulant heparin to the artificial blood, and this procedure usually prevented any flexions.

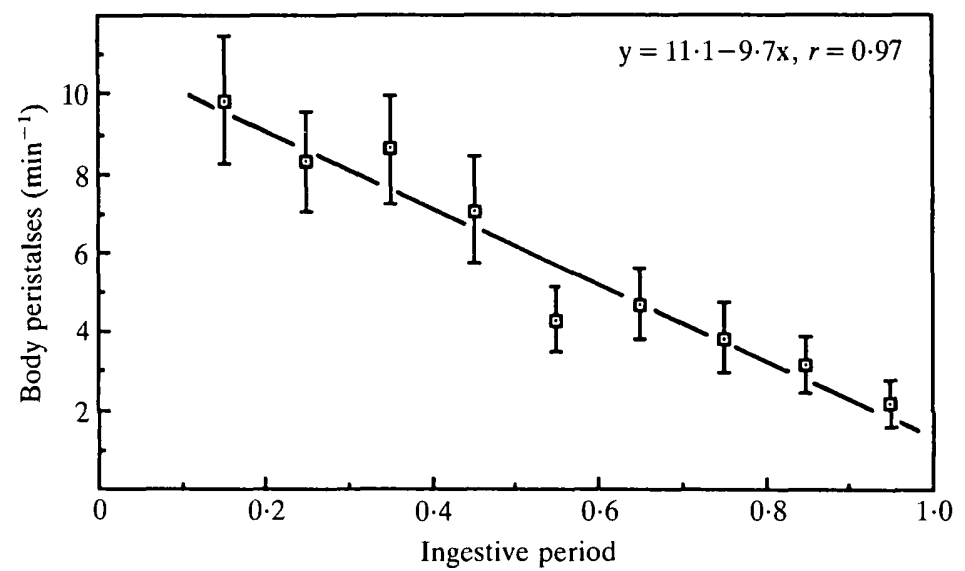

Fig. 4. Body wall peristalsis of Hirudo decreases during ingestion. The frequency of these movements was initially $10 \mathrm{~min}^{-1}$ and it decreased to $2 \mathrm{~min}^{-1}$ at termination of ingestion. The least squares equation for these points is linear. 


\section{Meal size}

Hirudo ingest voluminous meals. The leeches in this study had an average mass of $1.35 \pm 0.038 \mathrm{~g}(N=119)$ and they ingested $8.85 \pm 0.22 \mathrm{~g}(N=119)$ of blood. The initial size of the leeches influenced meal size: large leeches ingested somewhat more blood than small ones. Thus Fig. 5A shows that a 1-g leech ingested $8.4 \mathrm{~g}$ of blood and a $2-\mathrm{g}$ leech $9.7 \mathrm{~g}$. However, most previous reports of leech feeding have emphasized the relative size of their blood meals (Sawyer, 1986). The average $1 \cdot 35$-g leech ingested a volume of blood of $7 \cdot 00 \pm 0 \cdot 22$ times $(N=119)$ its mass.
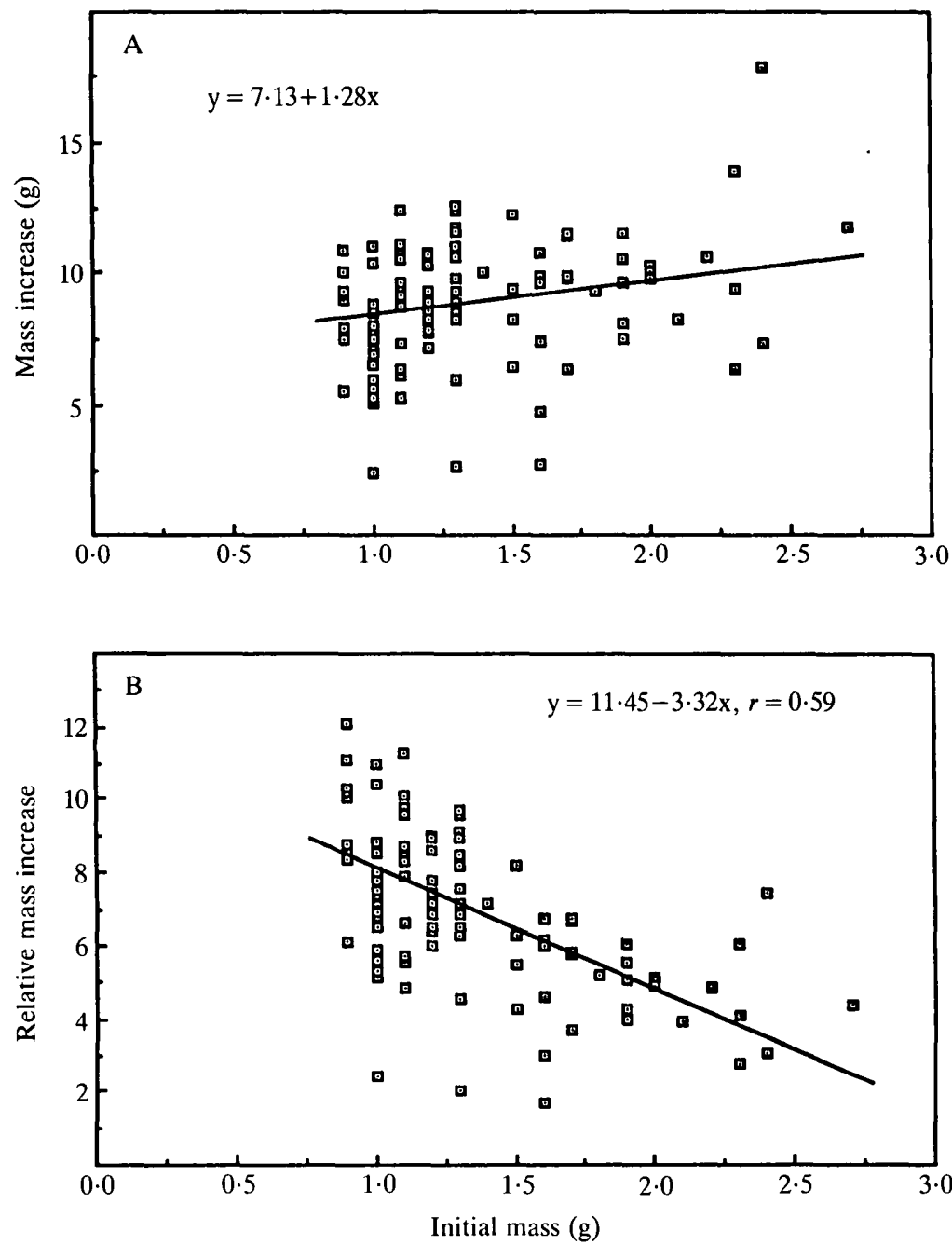

Fig. 5. Blood meal size of Hirudo. (A) Absolute size of blood meals as a function of the initial mass of the leech. Size of meals increases slightly as a function of initial mass and the linear equation differs significantly from zero $(P<0 \cdot 05)$. (B) Relative meal size as a function of initial mass. Relative volume decreases linearly. 
Relative meal size decreased markedly with body size (Fig. 5B) and the relationship was linear $(r=0.59)$. The 1 -g leech ingested 8.15 times its mass in blood and the 2-g leech 4.80 times. Thus, whereas absolute meal size increased slightly with leech size, relative size of blood meals decreased markedly.

\section{Serotonin}

Salivation and pharyngeal contractions are physiological components of leech ingestion activated by neuronal serotonin (Lent \& Dickinson, 1984). Similarly, behavioural components of leech ingestion were altered by exposure of leeches to dilute serotonin. The initial rate of pharyngeal peristalsis increased from $2 \cdot 3 \mathrm{~Hz}$ to $2.8 \mathrm{~Hz}(P<0.05$, Fig. 6A), but, between 0.15 and 0.35 of the ingestive period, pharyngeal rate appeared to be depressed slightly below control values
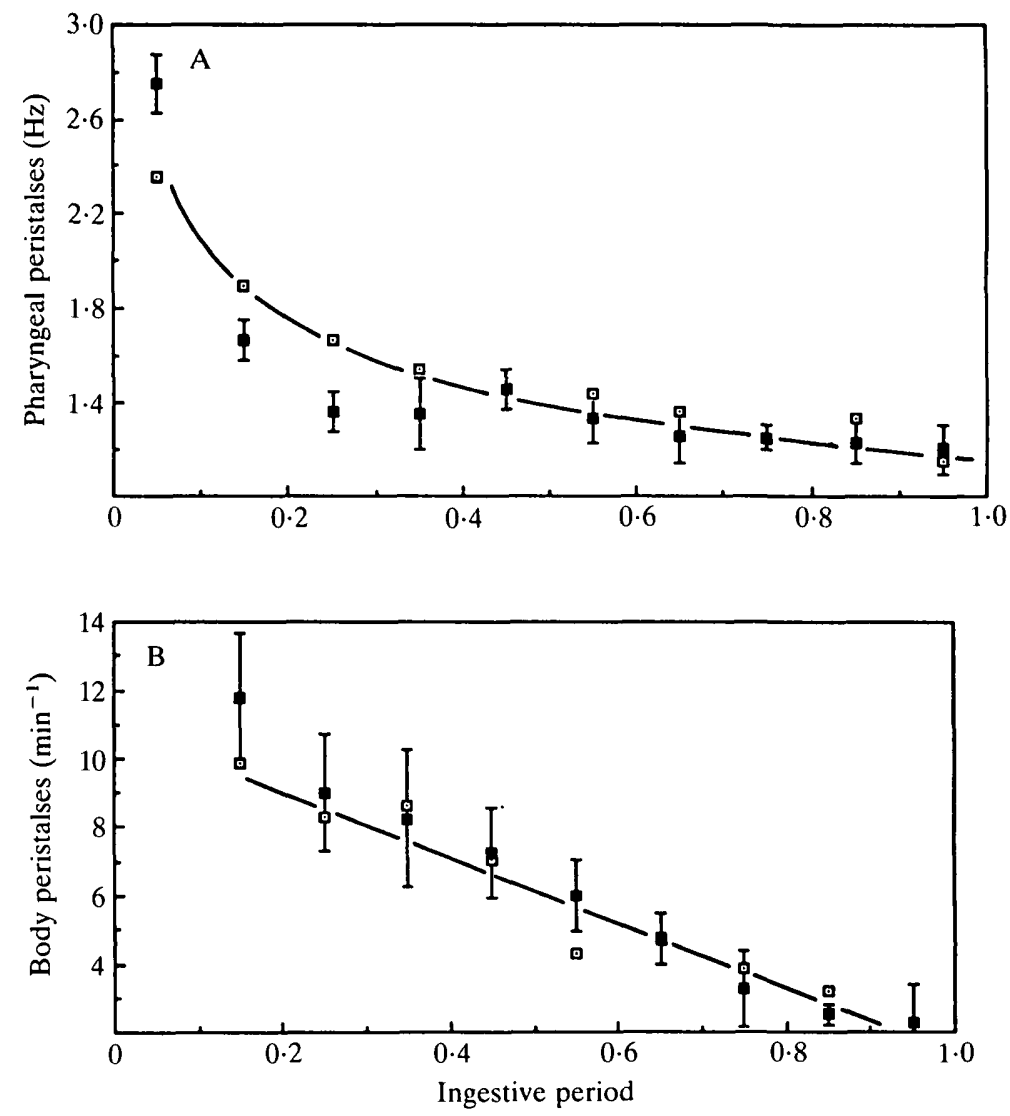

Fig. 6. Effects of serotonin (5-HT) on leech feeding behaviour. Control means ( $\square$ ) and estimating equations are plotted together with means \pm 1 s.E.M. of the 5-HTtreated animals ( $(\mathbf{D})$. (A) Pharyngeal peristalsis. The initial rate is elevated to $2 \cdot 8 \mathrm{~Hz}$, significantly higher than that of controls, $2 \cdot 3 \mathrm{~Hz}$. The rate appears depressed $(0.05<P<0 \cdot 10)$ between 0.15 and 0.35 of the feeding period. (B) Serotonin and body wall peristalsis. The initial increase to $12 \mathrm{~min}^{-1}$ is slightly higher than the control value of 10 and the probability that they are the same is $P=0.055$. 
$(0 \cdot 05<P<0 \cdot 10)$. During the last half of the ingestive period, 5-HT had no effect on pharyngeal movements. The effect of 5-HT on body wall peristalsis had a similar temporal pattern (Fig. 6B) and the initial rate was elevated to $12 \mathrm{~min}^{-1}$, only slightly higher than the control rate of $10 \mathrm{~min}^{-1}(P=0.055)$.

After a 5-HT bath, leeches ingested blood meals of $10.07 \pm 0.31 \mathrm{~g}(N=67)$, significantly higher than the $8.85 \mathrm{~g}$ of controls ( $t$-test, unpaired comparisons, $P<0.001)$. The relative blood meal size of 7.0 times body mass was also increased to $7.6 \pm 0.29(N=67)$ by the exposure $(P<0.015)$. The ingestive duration of $24.7 \mathrm{~min}$ was $2 \mathrm{~min}$ longer after 5 -HT treatment, $26.8 \pm 1.85 \mathrm{~min}(N=67)$, but this effect is not statistically significant.

\section{Excretion}

Leeches are obviously distended by ingestion, but over 1-2 weeks, the distension appears to decrease and they regain some of their lost mobility. To quantify this phenomenon, we measured the daily mass of 10 Hirudo (1-1.3 g) for 12 days immediately following ingestion. The post-fed mass of this group was 8.60 times their pre-fed mass. Total body mass decreased rapidly for 4 days and stabilized at 3.60 times initial mass on day 6 (Fig. 7A). Even though some of their distension remained, the mass reduction, of five times their pre-fed mass, partially restored locomotor capacity. This postingestive mass loss represents approximately $60 \%$ of the mass of the ingested blood, a proportion which approximates the plasma volume of the ingestate. To determine whether postingestive mass loss was accomplished by an excretion of plasma from ingested blood, we measured the haematocrit of leech crop contents. Blood samples were taken from the crops of 20 leeches which had fed 6-14 days earlier. The haematocrit of the artificial blood upon which they had fed ranged between 25 and $40 \%$. The crop contents of each leech had a haematocrit of $100 \%$. No plasma was detected in any of 100 crop samples after sedimentation at $5000 \mathrm{~g}$.

We attempted to assess postingestive excretion directly by placing dyes in the blood before ingestion, and then observing the appearance of colour in the pond water which held the fed leeches. Fast green, neutral red and toluidine blue coloured the artificial blood effectively, but none of these was excreted into the pond water in visible amounts. However, the dyes were good indicators of postingestive regurgitation, which occurred in about $10 \%$ of the leeches over a period of 8 weeks.

To ascertain whether the changes in the blood cell to plasma ratio were sufficient to account for the postingestive mass decreases, crop samples were collected from different leeches at daily intervals after feeding. As Fig. 7B shows, the haematocrit of the ingestate increased throughout the period of mass loss and reached $100 \%$ by day four. Simple calculations on these haematocrit and mass changes demonstrate readily that the excretion of blood plasma accounts for all the postingestive mass loss by Hirudo.

To determine whether the clear fluid, which flows from the skin of the feeding leech (Worth, 1951) resulted from excretion during ingestion, we sampled the crop 

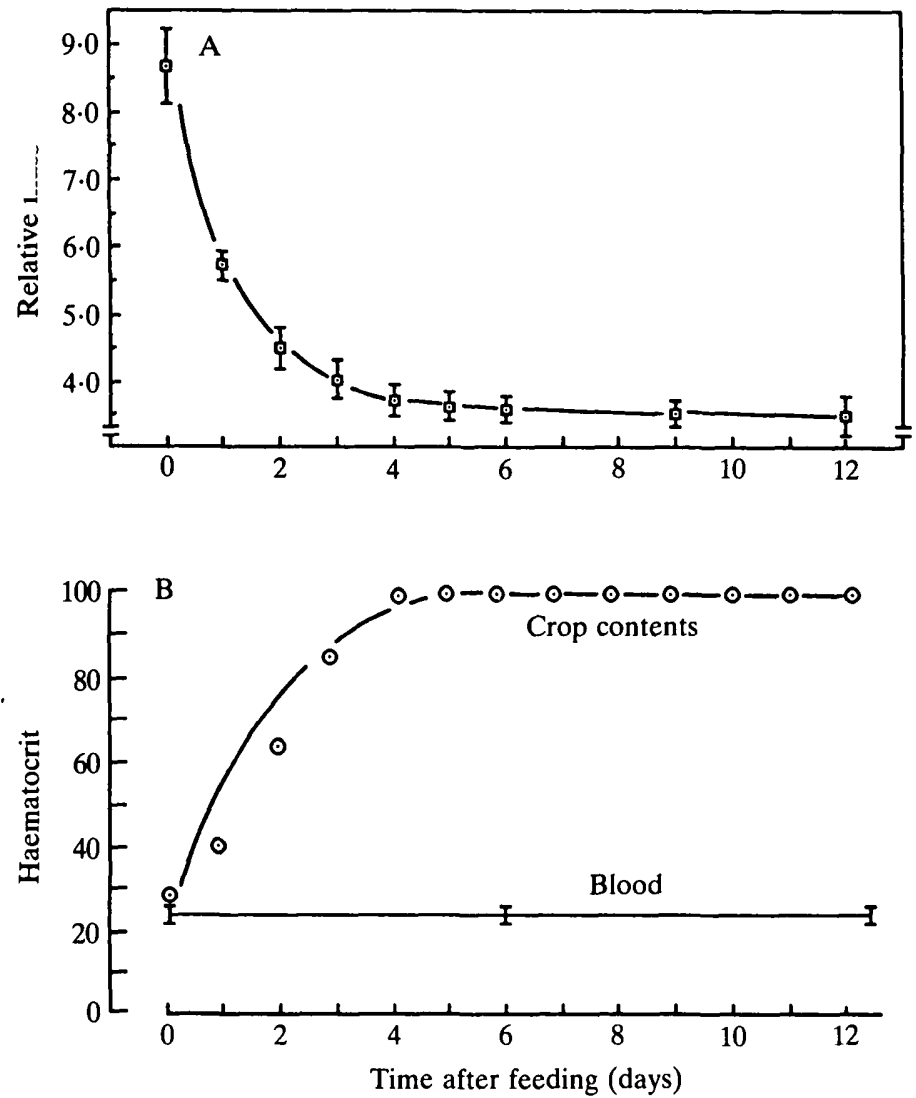

Fig. 7. Ingestion and excretion by Hirudo. (A) Leech mass decreases following ingestion. The average mass of 10 fed leeches $(1 \cdot 0-1 \cdot 3 \mathrm{~g})$ decreased from an initial value of 8.7 (times pre-fed levels) and reached an asymptote of 3.60 times pre-fed level by day 6 . Most of the mass was lost in the first 4 days and the rate of change exceeded that of an exponential function. (B) The proportion of blood cells (haematocrit) in the leech ingestate increases over the first 4 days following feeding. From day 6 to day 20 the crops of 20 leeches contained $100 \%$ erythrocytes (no plasma). Error bars on the haematocrit of the artificial blood represent \pm 1 S.E.M.

contents of 10 leeches immediately upon termination of ingestion. Every crop sample (50 replicates) had more cells than the blood in the feeding tube. The haematocrit of the blood in the feeding tubes was $25.7 \pm 0.5 \%(N=10)$ and that of the crop contents $28 \cdot 2 \pm 2 \cdot 1 \%(N=10)$. This increase in haematocrit is statistically significant $(P<0.05 ; t$-test for paired comparisons) and represents a $10 \cdot 2 \%$ increase in the relative volume of blood cells in the ingestate.

It was necessary to ensure that leeches did not increase the blood cell volume of their crop contents by selectively ingesting cells over plasma. We tested this possibility in five experiments by measuring the haematocrit of the blood within a eding tube immediately before and after a leech fed upon it. The haematocrit in each tube never changed after feeding by more than $0.2 \%$ of its pre-feeding value 
(25 paired replicates). The haematocrit of every leech crop sample was at least $1.0 \%$ higher than that of its feeding tube (50 replicates). There is, therefore, no indication that cells settle to the bottom of the feeding tube and/or that cells are selectively harvested by the leech. Thus, leeches excrete plasma during ingestion and this process increases feeding efficiency. The ingestate has more cells, and therefore more protein, than the whole blood upon which Hirudo feed.

Anecdotal evidence supports these observations of ingestive excretion. The fluid which flows from Hirudo feeding on a human is usually clear. In one such experiment, the fluid exuding from the leech feeding on an individual was yellow. A blood sample, taken from that individual, revealed a yellow pigment in his plasma. This observation suggested that the exuding fluid was coloured because the leech was excreting plasma during ingestion, and it provided the impetus for these experiments.

\section{Discussion}

The context in which Hirudo feeds affects the duration of ingestive behaviour. When submerged and feeding upon whole blood, Hirudo ingest for about $25 \mathrm{~min}$. If leeches feed upon tissue culture fluid lacking erythrocytes they ingest one-third as much in about $8 \mathrm{~min}$ (Lent \& Dickinson, 1987). Further, if leeches feed in air rather than submerged, they ingest about half as much blood in half the time (unpublished observations). The rhythmic movements of the pharynx pump blood into the crop, and an average leech contracts its pharynx approximately 2500 times in ingesting a satiating meal. The rate of pharyngeal peristalsis decays logarithmically; but in leeches which do not distend during ingestion (i.e. those with incised body walls; Lent \& Dickinson, 1987), the rate does not decrease as rapidly. This observation suggests that body wall distension has a role in slowing pharyngeal peristalsis. A logarithmically decreasing time course could be produced mechanically. Increasing pressure on the crop fluid as ingestion proceeds would require each contraction to develop more contactile force, lowering pharyngeal frequency. The decay could also be produced by a central mechanism. Identified neurones release serotonin peripherally which excites the pharynx (Lent \& Dickinson, 1984), and distension receptors in the body inhibit these neurones (Lent \& Dickinson, 1987). An increasing inhibition arising from distensive synaptic input as ingestion proceeds could reduce the firing rates of serotonergic neurones and result in decreased levels of peripheral serotonin which, in turn, would slow peristalsis. It should be noted that the addition of warm blood to the feeding tube during ingestion does not increase pharyngeal frequency, and thus the decay does not result from a cooling of the blood in the feeding tube.

The peristaltic and antiperistaltic movements of the leech body wall appear to be a mechanism for distributing the ingested blood uniformly throughout the crop. The Hirudo crop is a capacious storage organ which fills the body and has 11 paizof lateral diverticula, the most posterior pair of which is exceptionally elongat (Sawyer, 1986). To maximize meal volume, the incoming blood must fill these 22 
caecal pockets. Body wall peristalses force the ingested blood back and forth along the central chamber of the crop, and this longitudinal flow probably facilitates the lateral movement of blood through the small orifices of the diverticular chambers.

Dorsoventral flexions of the body were seen when clots formed in the feeding tube and were absent, or highly attenuated, when anticoagulant was added to the artificial blood. Flexions were more robust towards the end of feeding bouts, when clots would have enlarged and become more occlusive. Dorsoventral flexions might be a leech behaviour which dislodges clots and maintains an adequate flow of blood from skin incisions whenever the salivary anticoagulant hirudin proves ineffective.

Excretion is a major physiological component of leech ingestion. Fluid excretion during ingestion increases the efficiency of leech feeding. By excreting the plasma from incoming blood, the crop can be made to contain more cells than an equal volume of whole blood. For a 1-g leech the observed increase represents approximately $4 \times 10^{9}$ erythrocytes more than the number in an equal volume of whole human blood. The haemoglobin in mammalian erythrocytes is a primary source of Hirudo dietary protein (Windsor, 1970) and linking excretion with ingestion provides Hirudo with more digestible protein and enables the leech not to feed for a full year.

After ingestion is terminated, the continued excretion of plasma restores some of the mobility which the leech lost as a result of ingesting a voluminous meal. Although blood cells are concentrated by excretion for 4-5 days, their volume is not insubstantial and this distension is alleviated only slowly by digestion. Hirudo lyse their ingested erythrocytes, digest the protein of the haemoglobin within their short intestine and egest the porphyrin, haem (Windsor, 1970).

Small animals generally have higher rates of mass-specific metabolism and rhythmic movements than large ones (Schmidt-Nielsen, 1984). This size principle pertains to leech metabolism (Kulkarni \& Nagabushanum, 1978) and is reflected in the differing pharyngeal frequencies reported here. Small leeches are likely to require relatively more energy than large ones during the long period of satiation because of higher mass-specific metabolism. Thus, metabolic differences resulting from leech size should affect meal volume such that relative meal size should decrease with increasing leech mass. This is precisely what we see in the sizes of the meals ingested by adult Hirudo (Fig. 5B). However, we have also fed five $0 \cdot 5$-g leeches and these juveniles ingested only between 1 and $1.5 \mathrm{~g}$ of blood: $2-3$ times their initial mass. Such small meal sizes in leeches with high metabolic rates combine a limited source of energy with a high rate of consumption. Thus, juvenile Hirudo probably feed more often than once a year. Juveniles of the South American leech Haementeria feed more frequently than mature specimens (Sawyer, 1986).

Leech ingestion comprises stereotyped muscular movements, salivary secretion and nephridial excretion. During ingestion, pharyngeal contractions and salivation re activated by serotonin which is released peripherally by impulse activity of identified neurones (Lent \& Dickinson, 1984). Serotonin neurones are synaptically 
excited into impulse activity by ingestive stimuli and are synaptically inhibited by the distensive stimulus, and cease firing (Lent \& Dickinson, 1987). Excretion is activated concomitantly with ingestion but continues for several days. Hence, the mechanism responsible for the long-term activation of excretion differs, at least quantitatively, from the mechanism for the short-term activation of pharyngeal muscles and salivary glands.

Exposing intact Hirudo to serotonin affects components of feeding behaviour: swim initiation, biting frequency and relative blood meal size (Lent \& Dickinson, 1984). We find that exogenous 5-HT increases the absolute, as well as the relative, size of Hirudo blood meals. A brief exposure to serotonin also transiently increases the rate of pharyngeal peristalsis. Since the exposure has no significant effect on duration of ingestion, serotonin probably increases leech meal size by its effect on pharyngeal peristalsis. Serotonin also reduces the resting tension of leech body muscles (Mason \& Kristan, 1982), a peripheral effect which undoubtedly assists the pharynx in filling a more compliant body. Exogenous serotonin probably exerts behavioural effects by activating peripheral receptors via the leech skin. At least three chemicals, 5-HT (Glover \& Kramer, 1982), its neurotoxic analogue 5,7-dihydroxytryptamine (Glover, 1987) and neutral red dye (Lent, 1981), reach internal structures of the intact leech from the bathing medium.

Sanguivorous feeding by the nymphs of the bug Rhodnius resembles that of Hirudo in several aspects. Rhodnius ingest blood meals of 6-7 times their mass and the resulting distension terminates ingestion (Maddrell, 1963). The saliva of Rhodnius has anticoagulant activity (Ribeiro \& Garcia, 1980). Excretion is activated as Rhodnius feeds, which must increase the proportion of blood cells to plasma in the ingestate and, after feeding, excretion continues as postingestive diuresis (Maddrell, 1964). These are striking functional similarities in feeding by a blood-sucking annelid and a blood-sucking insect and yet these functions rely upon anatomically disparate organ systems. Efficient sanguivory upon mammalian blood may necessitate the convergent evolution of a similar set of physiological mechanisms.

We thank David R. Smith and David Zundel for technical assistance with some of these experiments. This research was supported by PHS grants NS-14482 and NS-24077 to CML.

\section{References}

Dickinson, M. H. \& Lent, C. M. (1984). Feeding behavior of the medicinal leech, Hirudo medicinalis L. J. comp. Physiol. A 154, 449-455.

Elliot, E. (1986). Chemosensory stimuli in leech feeding: An important role for $\mathrm{NaCl}$ and arginine. J. comp. Physiol. A 159, 391-401.

Glover, J. G. (1987). Serotonin storage and uptake by identified neurons in the leech Haementeria ghilianii. J. comp. Neurol. 256, 117-127.

Glover, J. G. \& Kramer, A. P. (1982). Serotonin analogue selectively ablates identified neurons in the leech embryo. Science 216, 1012-1014.

HAycraft, J. B. (1884). On the action of a secretion obtained from the medicinal leech on the coagulation of blood. Proc. R. Soc. Ser. B 36, 478-487. 
Kristan, W. B., JR, Stent, G. S. \& Ort, C. A. (1974). Neuronal control of swimming in the medicinal leech. I. Dynamics of the swimming rhythm. J. comp. Physiol. 94, 97-119.

Kulkarni, G. K. \& Nagabushanum, R. (1978). Respiratory metabolism of Indian leech Poecilobdella viridis: influence of body size. Marathwada Univ. J. Sci. 17, 97-100.

LENT, C. M. (1981). Morphology of neurons containing monoamines within leech segmental ganglia. J. exp. Zool. 216, 311-316.

LENT, C. M. (1986). New medical and scientific uses of the leech. Nature, Lond. 323, 494.

Lent, C. M. \& Dickinson, M. H. (1984). Serotonin integrates the feeding behavior the medicinal leech. J. comp. Physiol. A 154, 457-471.

Lent, C. M. \& Dickinson, M. H. (1987). On the termination of ingestive behaviour by the medicinal leech. J. exp. Biol. 31, 1-15.

Lent, C. M., Fliegner, K. \& Freedman, E. (1986). Ingestive behavior of the medicinal leech. Soc. Neurosci. Abstr. 12, 407.

MAdDrell, S. H. P. (1963). Control of ingestion in Rhodnius prolixus Stål. Nature, Lond. 198, 210.

Maddrell, S. H. P. (1964). Excretion in the blood-sucking bug, Rhodnius prolixus Stål. II. The normal course of diuresis and the effect of temperature. J. exp. Biol. 41, 163-176.

Marshall, C. G. (1984). The salivary glands of the Hirudinea: Electrophysiology, structure and secretion. Ph.D. dissertation, Brown University, Providence, RI.

Mason, A. \& Kristan, W. B. JR (1982). Neuronal excitation, inhibition and modulation of leech longitudinal muscle. J. comp. Physiol. 146, 527-536.

Muller, K. J., Nicholls, J. G. \& Stent, G. S. (eds) (1981). Neurobiology of the Leech. New York: Cold Spring Harbor Laboratory Press.

Ribeiro, J. M. C. \& GARCIA, E. S. (1980). The salivary and crop apyrase activity of Rhodnius prolixus. J. Insect Physiol. 26, 303-307.

SAWyer, R. T. (1986). Leech Biology and Behaviour. Oxford: Clarendon Press.

Schmidt-Nielsen, K. (1984). Scaling: Why is Animal Size so Important? London: Cambridge University Press.

Sokal, R. R. \& Rohlf, F. J. (1981). Biometry, 2nd edn. San Francisco: Freeman.

WINDSOR, D. A. (1970). Faeces of the medicinal leech, Hirudo medicinalis, are haem. Nature, Lond. 227, 1153-1154.

WorTH, C. B. (1951). Description and discussion of the biting of an Indian land leech (Annelida: Hirudinea). J. Bombay nat. Hist. Soc. 510, 423-426.

ZerbSt-BorofFKa, I. (1973). Osmo- und Volumenregulation bei Hirudo medicinalis nach Nahrungsaufnahme. J. comp. Physiol. 127, 343-347. 